\title{
Prevalence of Caries in Permanent First Molars Among Children with and Without Caries on Primary Teeth- A Retrospective Study
}

\author{
Anupama Deepak ${ }^{1}$, EMG Subramaniam ${ }^{2}$, Ganesh Jeevanandan ${ }^{3 *}$ and M. Jeevitha ${ }^{4}$ \\ ${ }^{1}$ Saveetha Dental College and Hospitals, Saveetha Institute of Medical \\ and Technical Sciences, Saveetha University, Chennai, India \\ ${ }^{2,3}$ Department of Pediatric and Preventive Dentistry,Saveetha Dental College and Hospitals, \\ Saveetha Institute of Medical and Technical Sciences, Saveetha University, Chennai,India \\ ${ }^{4}$ Department of Periodontics, Saveetha Dental College and Hospitals, Saveetha Institute \\ of Medical and Technical Sciences, Saveetha University, Chennai,India \\ Corresponding author email: ganesh.sdc@saveetha.com
}

\begin{abstract}
Dental caries in the form of early childhood caries is more prevalent in children. Severe form of caries extending throughout the coronal structure in the root can result in tooth pain. Children presenting with class II caries have been exposed to caries involving the pulp. Early childhood caries is one of the most infectious diseases of childhood having a chronic progression rate resulting in the destruction of tooth structure. Permanent first molars are the first permanent teeth to erupt in the oral cavity at 6 years of age and have a higher rate of caries pattern than other teeth. This is associated with unusual dietary patterns and improper feeding patterns in children with prolonged use of baby bottles for milk feeding. Caries in children was mainly caused by the bacteria Streptococcus mutans. The aim of this study was to assess the prevalence of caries in permanent teeth in children with and without caries in primary teeth. A retrospective study was carried out using digital records of 875 subjects, irrespective of the gender. These data were collected from DIAS and coded in MS Excel sheets. The collected data was analysed by computer software SPSS version 21 using Chi square test and graphical illustration was done. From the above study, it was found that the high caries prevalence was seen in permanent teeth without caries in the primary teeth in males $(52.33 \%)$ and predominantly in the 6-9 years age group. Therefore, it can be concluded that permanent molars in children are a source of caries than the primary teeth and awareness should be created on dental caries among school children and parents.
\end{abstract}

\section{KEY WORDS: CHILDREN, DENTAL CARIES, PERMANENT FIRST MOLARS, PRIMARY TEETH.}

\section{INTRODUCTION}

Dental caries is seen worldwide affecting both the primary and permanent dentition in children. Permanent first molars are important for their morphological and functional characteristics. This is a multifactorial disease. Prevalence for forts molars is seen with all ages, in which the occlusal areas are commonly affected. Permanent first molars are the

Biosc Biotech Res Comm P-ISSN: 0974-6455 E-ISSN: 2321-4007
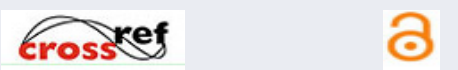

Identifiers and Pagination Article Information

Year: 2021 Vol: 14 No (10) Special Issue

Pages: $90-96$

Received: 09 $9^{\text {th }}$ Aug 2021

This is an open access article under Creative

Commons License Attribn 4.0 Intl (CC-BY).

DOI: $h t t p: / / d x$.doi.org/10.21786/bbrc/14.10.15 key to occlusion in the oral cavity. Loss of this can result in malocclusion and can have an impact on the future dental health. Permanent firs pt molars are the first permanent teeth to develop in the oral cavity around 6 years of age. They control the eruption of other teeth in the oral cavity. Mandibular first permanent molars have a greater number of pits and supplementary grooves; hence caries prevalence is more in such areas. Dental neglect and stress levels can result in less salivary secretion leading to caries formation. Studies have shown that malondialdehyde levels are at a high level in saliva which increases the risk for development of ECC (World Health Organization WHO., 1997; McDonald 
and Sheiham, 1992; Taani and Quteish, 2004; Gurunathan and Shanmugaavel, 2016; Aishwarya and Gurunathan, 2017; Subramanyam et al., 2018; Ivanova et al., 2018; Krishnaswamy et al., 2020).

Maxillary permanent first molars erupt after the mandibular molars and hence caries prevalence is comparatively less in the maxillary arch. According to the DMFT index, $\mathrm{D}$ component is more common. Teeth in the posterior region are more prone for caries than the anteriors. Caries assessment is seen more for proximal and occlusal caries in the permanent molars. Mesial surface caries has increased incidence followed by proximal surface caries. This is due to the food lodgement and class II caries seen on the proximal surfaces and improper tooth brushing. Among the growing children, frenal attachment plays a major role as it can result in midline diastema, and can result in spacing. Age and site of the tooth also plays a major role in caries prevalence. Occlusal caries was seen among young children and proximal caries among older children. Traumatic injuries can also result in fractured teeth and infections that can lead to caries formation (Edward, 1997; Lith et al., 2002; Hopcraft and Morgan, 2006; Christabel and Gurunathan, 2015; Packiri et al., 2017; Ravikumar et al., 2017; Ivanova et al., 2018; Venu et al., 2019; Krishnaswamy et al., 2020).

Treatment modalities for children with carious teeth are numerous. Caries extending to the pulp can be painful to the children and may require pulpectomy in primary teeth and root canal treatment for the permanent teeth. These are the various endodontic treatments carried out for the primary teeth in children. Pulpectomy is an endodontic procedure done in primary teeth which involves the removal of the pulpal tissue and retaining the tooth which forms a guidance for the eruption of permanent teeth. This procedure involves the instrumentation using files such as Kedo-S files which are the recent advances gaining importance in pulpectomy Techniques and quality of obturation differ on the type of files and the method used. Optimal fluoride content in the drinking water and usage of fluoridated toothpaste can prevent caries formation and progression. They form a protective layer on the tooth surface (Somasundaram et al., 2015; Jeevanandan, 2017; Jeevanandan and Govindaraju, 2018; Panchal et al., 2019)]. Mahesh, 2018; Nair et al., 2018; Govindaraju et al., 2017a, 2017b; Govindaraju et al., 2017; Panchal et al., 2019; Samuel et al., 2020)

Previously our team has a rich experience in working on various research projects across multiple disciplines (Gheena and Ezhilarasan, 2019; Ke et al., 2019; Malli Sureshbabu et al., 2019; Mehta et al., 2019; Samuel et al., 2019; Sharma et al., 2019; Varghese et al., 2019; Venu et al., 2019; Venu et al., 2019; Vignesh et al., 2019; Jain et al., 2019; Jose et al., 2020; Krishnaswamy et al., 2020; Muthukrishnan et al., 2020; Samuel et al., 2020; Sathish and Karthick, 2020). Now the growing trend in this area motivated us to pursue this project.Therefore the aim of this study was to determine the prevalence of caries in permanent first molars in children with and without caries in primary teeth.

\section{MATERIAL AND METHODS}

Study Design: This was a cross sectional study conducted at a university setting, Chennai. The data was collected from a digital case sheet record. The sample size of the study was 105 subjects from a total of 875 case sheet records of children of 6-13 years, irrespective of their gender. The pros of the study were similar ethnicity and cons were geographic limitations. The ethical approval was given by the ethics board of the university and data was reviewed by 2 viewers. 875 case sheets were reviewed. Simple random technique was used to minimise sampling bias. The internal validity was the caries in first molar and external validity was that data can be generalizable.

Figure 1: Representing the percentage of subjects treated based on age, with $\mathrm{X}$-axis representing the age and $\mathrm{Y}$-axis representing the percentage of subjects treated. Majority of the subjects $(84.8 \%)$ belonged to the $10-13$ years age group, whereas $15.2 \%$ belonged to the 6-9 years age group.

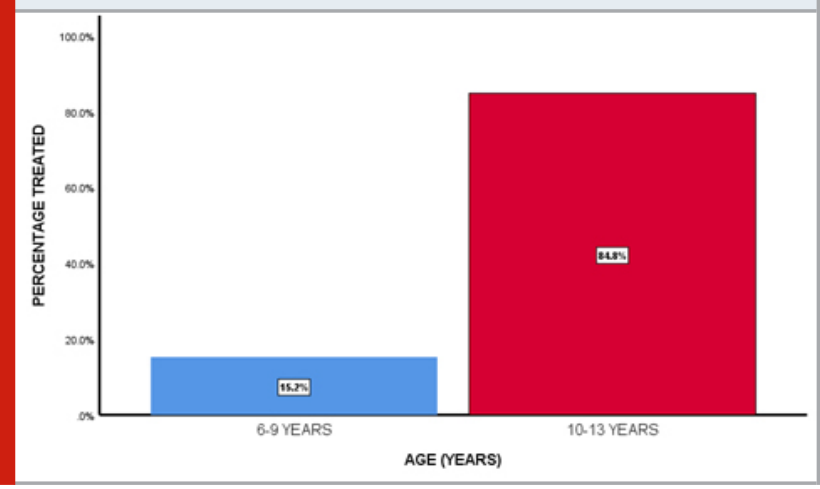

Figure 2: Representing the percentage of subjects treated based on gender, with $\mathrm{X}$-axis representing the gender and Y-axis representing the percentage of subjects treated. Majority of the subjects were males $52.4 \%$, whereas $47.6 \%$ of subjects were females.

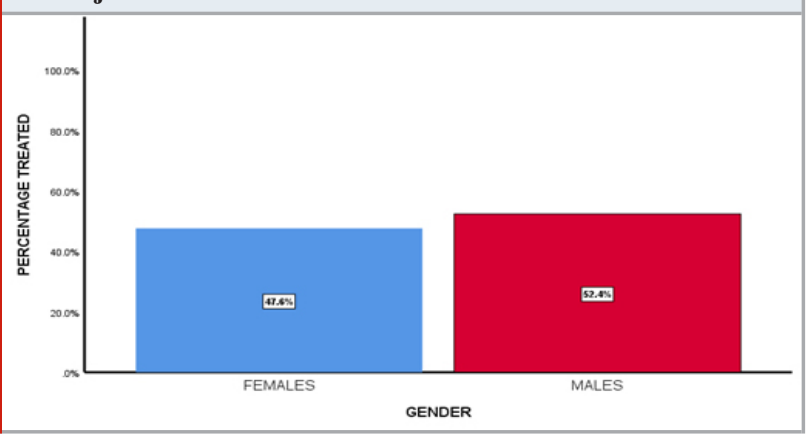

Data Collection/ Tabulation: Data was collected from a digital case sheet record using a software and was then transferred to MS Excel Sheet. Coding of data was done and tabulation was done in MS Excel spreadsheet. Data was then imported to SPSS by variable definition process.

Analytics: Data was analysed using SPSS IBM version 20.0. Descriptive and inferential statistics was used. List of 
dependent variables were caries in anterior teeth and those of independent variables were age and gender. Chi- square test was followed and data transferred to the host computer and graphical illustration was done.

\section{RESULTS AND DISCUSSION}

In the present study, from Figure 1, 84.8\% belonged to the $10-13$ years age group and $15.2 \%$ belonged to the $6-9$ years age group. From Figure 2, 52.4\% were males and $47.6 \%$ were females. From Figure 3, distribution of subjects with and without caries ,71.4\% of subjects had caries along with permanent teeth and $28.6 \%$ of subjects had no caries in primary teeth. From Figure 4, with caries in first molars, $52.4 \%$ had caries in mandibular first molars and $18.1 \%$ in maxillary first molars whereas $29.5 \%$ had caries in both. From Figure 5, on comparison of caries in primary teeth with age, prevalence was more in the $10-13$ years age group $(90.7 \%)$ with mean value of $1.2, \mathrm{SD}$ of 0.42 and $p$ value of 0.007 which is a statistically significant association. From Figure 6, on comparison of caries in primary teeth with gender, prevalence was more in males $(53.3 \%)$ with mean value of $1.2, \mathrm{SD}$ of 0.44 and $\mathrm{p}$ value of 0.76 which is a statistically insignificant association.

Figure 3: Representing the percentage of subjects treated based on caries in primary teeth, with $\mathrm{X}$-axis representing the caries in primary teeth and $Y$-axis representing the percentage of subjects treated. $71.4 \%$ of the subjects had caries in primary teeth whereas $28.6 \%$ had no caries in primary teeth.

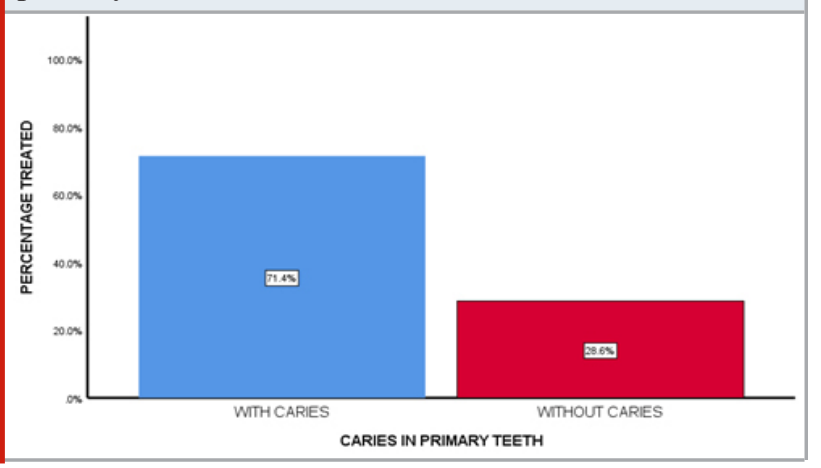

From Figure 7, on comparison of caries in permanent first molars with age, prevalence was more for the 10-13 years age group in the mandibular first molars (92.7\%) years with mean value of 1.9 , SD of 0.65 and $p$ value of 0.014 which is a statistically insignificant association. From Figure 8, on comparison of caries in permanent first molars with gender, prevalence was more in males in both maxillary and mandibular first molars $(61.3 \%)$ with mean value of $1.8, \mathrm{SD}$ of 0.69 and $\mathrm{p}$ value of 0.291 which is a statistically insignificant association. From Figure 9, on association between caries in primary teeth and permanent first molars based on Pearson Chi square test, the results were statistically significant at $\mathrm{p}<0.001$.

It is very important to understand the various effects of caries in first permanent molars in children. Caries prevalence, as seen from the above study, distal surface
Figure 4: Representing the percentage of subjects treated based on caries in permanent first molars, with $\mathrm{X}$-axis representing the caries in permanent first molars and $\mathrm{Y}$-axis representing the percentage of subjects treated. $52.4 \%$ of the subjects had caries in mandibular first molars (red), $18.1 \%$ had caries in maxillary first molars (blue), whereas $\mathbf{2 9 . 5 \%}$ had caries in both maxillary and mandibular first molars (green).

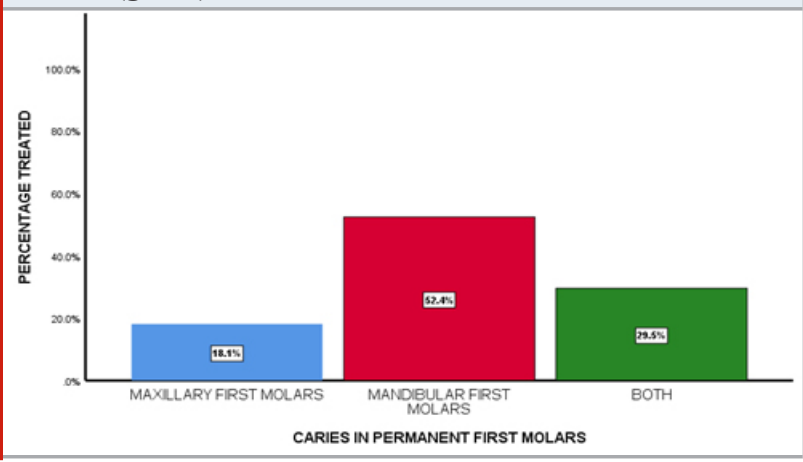

Figure 5: Representing the association between caries in primary teeth and age in subjects treated for caries, with $\mathrm{X}$-axis representing the age and $\mathrm{Y}$-axis representing the percentage of patients treated. 6-9 years age group had a mean value of $(1.5 \pm 0.51)$ in which $30 \%$ of the subjects were without caries in primary teeth (red), whereas 10-13 years age group had a mean value of $(1.2 \pm 0.42)$ in which $90.7 \%$ of subjects were with caries in primary teeth(blue), with a p-value of $0.007(<0.05)$ which is statistically significant, which means there is a significant association between the age and the presence of caries in primary teeth.

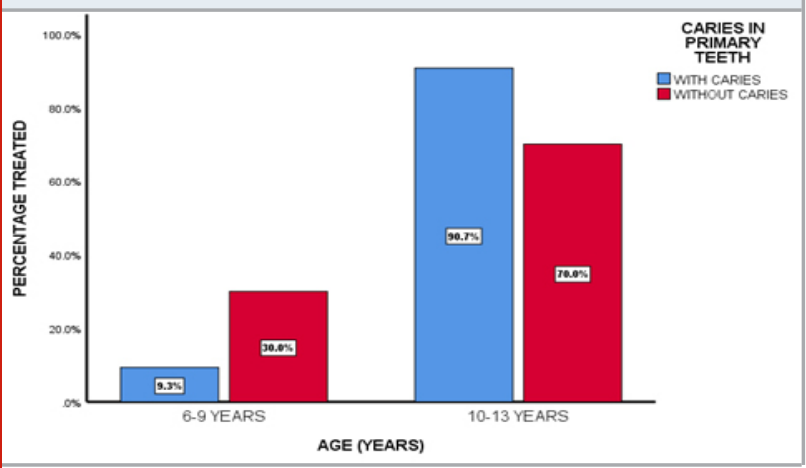

caries is less prominent which can be due to late formation of the contact with second molar. One of the reasons is lack of oral health maintenance. Several studies have been reported with similar concordance with the findings. A study in Jeddah showed the prevalence of caries in the first permanent molar was between 6 to 9 years. Another study showed a mean of 1.19 for caries prevalence in the molar whereas another study in Jeddah said caries prevalence was more for 6-12 years children with mean of 6.3 One of the recent advances is the chewable toothbrush that has been known to reduce the caries formation (Nordblad and Larmas, 1986; Al-Khateeb et al., 1991; Warren et al., 1997; Alamoudi et al., 2009; Govindaraju and Gurunathan, 2017; Krishnaswamy et al., 2020). 
Figure 6: Representing the association between caries in primary teeth and gender in subjects treated for caries, with $\mathrm{X}$-axis representing the gender and $\mathrm{Y}$-axis representing the percentage of patients treated. Females had a mean value of $(1.3 \pm 0.46)$ in which $50 \%$ of subjects were without caries in primary teeth (red), whereas males had a mean value of $(1.2 \pm 0.44)$ in which $53.3 \%$ of subjects were with caries in primary teeth (blue) with a p-value of $0.760(>0.05)$ which is statistically not significant which means there is no significant association between the gender and the presence of caries in primary teeth.

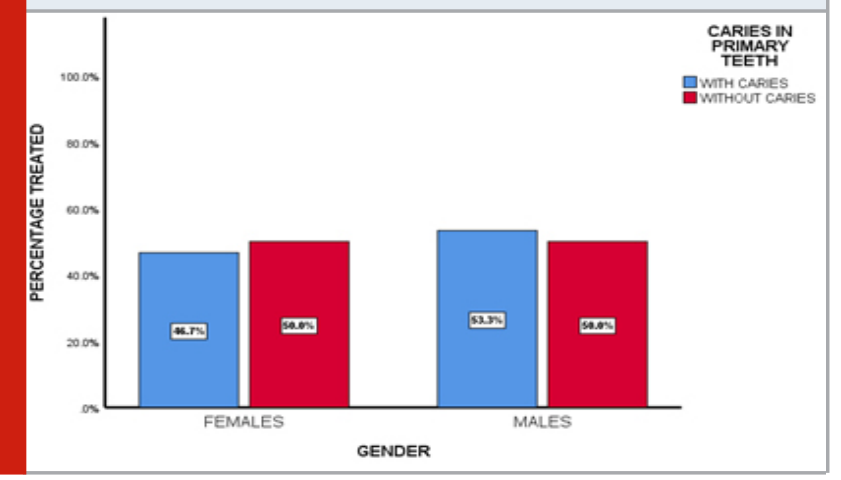

Figure 8: Representing the association between caries in permanent first molars and gender in subjects treated for caries, with $\mathrm{X}$-axis representing the gender and $\mathrm{Y}$-axis representing the percentage of patients treated. Females had a mean value of $(1.9 \pm 0.66)$ in which $52.6 \%$ of subjects had caries in maxillary first molars (blue), whereas males had a mean value of $(1.8 \pm 0.69)$ in which $61.3 \%$ of subjects had caries in both maxillary and mandibular first molars (green) and a p-value of $0.291(>0.05)$ which is statistically not significant which means there is no significant association between the gender and the presence of caries in permanent first molars.

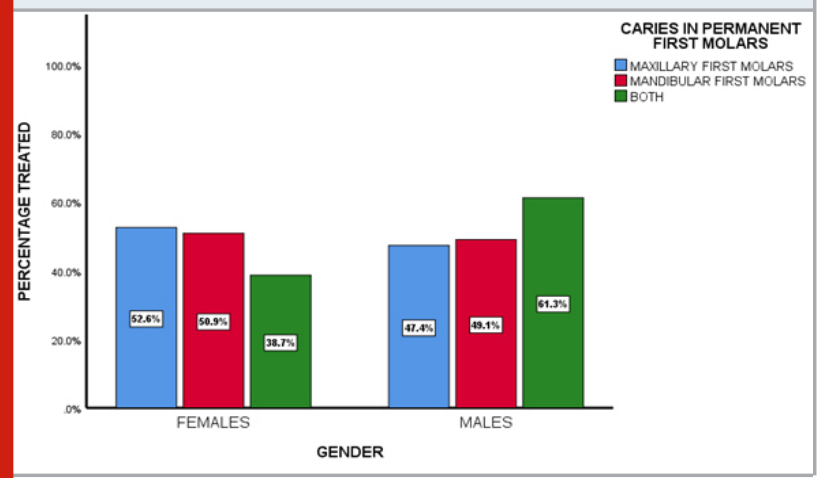

Cavitated lesions were more prone to be in primary teeth rather than the molar of permanent teeth. This can be due to the improper feeding practices. Studies contrary with the findings said caries prevalence was more for second primary molars. Some studies have reported decreased levels of caries both in primary and permanent teeth The present study has its own limitations such as the geographic limitation. A study performed in North Palestine said the caries prevalence is more for primary dentition with mean
Figure 7: Representing the association between caries in permanent first molars and age in subjects treated for caries, with $\mathrm{X}$-axis representing the age and $\mathrm{Y}$-axis representing the percentage of patients treated. 6-9 years age group had a mean value of $(1.5 \pm 0.73)$ in which $32.3 \%$ of subjects had caries in both maxillary and mandibular first molars (green), whereas 10-13 years age group had a mean value of $(1.9 \pm 0.65)$ in which $92.7 \%$ had caries in mandibular first molars and a p-value of $0.01(<0.05)$ which is statistically significant, which means there is a significant association between the age and the presence of caries in permanent first molars.

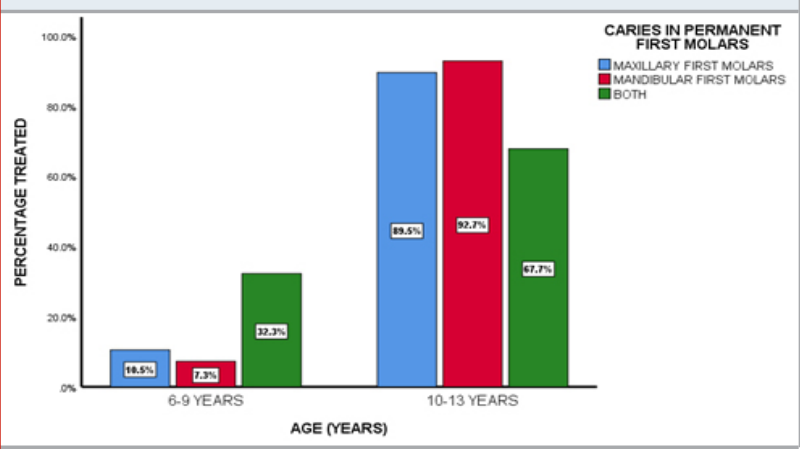

Figure 9: Represent the association between caries in primary teeth and permanent first molars based on Pearson Chi square test; the results were statistically significant at $\mathbf{p}<\mathbf{0 . 0 0 1}$.

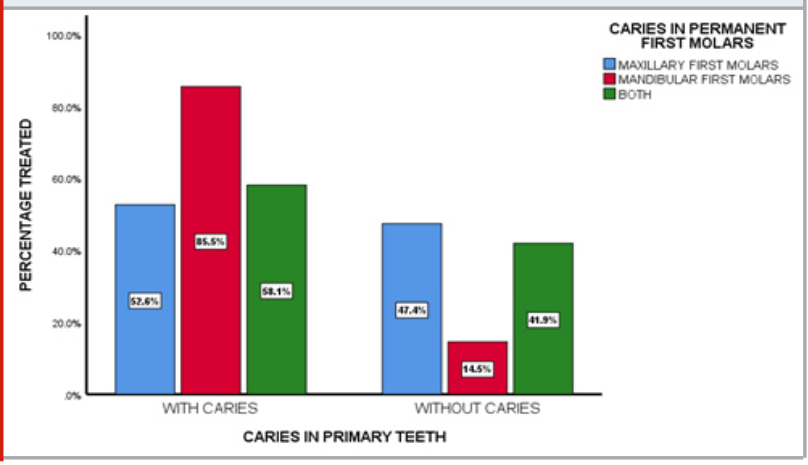

of 4.34 The future scope of the study is to create awareness in dental caries among children and parents providing oral health maintenance progress (Wyne, 2008; Wyne et al., 2002; Khan, 2014; Nair et al., 2018; Ke et al., 2019; Krishnaswamy et al., 2020).

Our institution is passionate about high quality evidence based research and has excelled in various fields (Pc et al., 2018; Ramesh et al., 2018; Ezhilarasan et al., 2019; Ramadurai et al., 2019; Sridharan et al., 2019; Vijayashree, 2019; Mathew et al., 2020). We hope this study adds to this rich legacy.

\section{CONCLUSION}

In conclusion, high prevalence of caries in permanent mandibular first molars was seen along with caries in the primary teeth in the age group of 10-13 years. 


\section{ACKNOWLEDGEMENTS}

The authors would like to acknowledge the support rendered by The Department of Pediatric and Preventive Dentistry of Saveetha Dental College and Hospitals and the management for their constant assistance with the research.

Conflicts of Interest: There are no conflicts of interest.

\section{REFERENCES}

Aishwarya, A. and Gurunathan, D. (2017). Stress level in dental students performing pedodontic procedure. J Adv Pharm Educ Res, 7(1).

Alamoudi, N., Salako, N. O. and Massoud, I. (2009). Caries experience of children aged 6-9 years in Jeddah, Saudi Arabia. International Journal of Paediatric Dentistry, pp. 101-105. doi: 10.1111/j.1365-263x.1996.tb00220.x.

Al-Khateeb, T. L., Al-Marsafi, A. I. and O'Mullane, D. M. (1991). Caries prevalence and treatment need amongst children in an Arabian community. Community Dentistry and Oral Epidemiology, pp. 277-280. doi: 10.1111/j.16000528. 1991.tb00167.x.

Christabel, S. L. and Gurunathan, D. (2015). Prevalence of type of frenal attachment and morphology of frenum in children, Chennai. Tamil Nadu', World J Dent.

Edward, S. (1997). Dental caries on adjacent approximal tooth surfaces in relation to order of eruption. Acta odontologica Scandinavica, 55(1), pp. 27-30.

Ezhilarasan, D., Apoorva, V. S. and Ashok Vardhan, N. (2019). Syzygium cumini extract induced reactive oxygen species-mediated apoptosis in human oral squamous carcinoma cells. Journal of oral pathology \& medicine: official publication of the International Association of Oral Pathologists and the American Academy of Oral Pathology, 48(2), pp. 115-121.

Gheena, S. and Ezhilarasan, D. (2019). Syringic acid triggers reactive oxygen species-mediated cytotoxicity in HepG2 cells. Human \& experimental toxicology, 38(6), pp. 694-702.

Govindaraju, L. and Gurunathan, D. (2017). Effectiveness of Chewable Tooth Brush in Children-A Prospective Clinical Study. Journal of clinical and diagnostic research: JCDR, 11(3), pp. ZC31-ZC34.

Govindaraju, L., Jeevanandan, G. and Subramanian, E. (2017). Clinical Evaluation of Quality of Obturation and Instrumentation Time using Two Modified Rotary File Systems with Manual Instrumentation in Primary Teeth. Journal of clinical and diagnostic research: JCDR, 11(9), pp. ZC55-ZC58.

Govindaraju, L., Jeevanandan, G. and Subramanian, E. M. G. (2017a). Comparison of quality of obturation and instrumentation time using hand files and two rotary file systems in primary molars: A single-blinded randomized controlled trial. European journal of dentistry, 11(3), pp.
376-379.

Govindaraju, L., Jeevanandan, G. and Subramanian, E. M. G. (2017b). Knowledge and practice of rotary instrumentation in primary teeth among indian dentists: A questionnaire survey. Journal of International Oral Health, 9(2), p. 45.

Gurunathan, D. and Shanmugaavel, A. K. (2016). Dental neglect among children in Chennai. Journal of the Indian Society of Pedodontics and Preventive Dentistry, 34(4), pp. 364-369.

Hopcraft, M. S. and Morgan, M. V. (2006). Pattern of dental caries experience on tooth surfaces in an adult population. Community dentistry and oral epidemiology, 34(3), pp. 174-183.

Ivanova, G. et al. (2018). The importance of upper first permanent molars position for the orthognatic occlusion. Scripta Scientifica Medicinae Dentalis, p. 41. doi: 10.14748/ssmd. v3i2.4332.

Jain, S. et al. (2019). Evaluation of Three-Dimensional Changes in Pharyngeal Airway Following Isolated Lefort One Osteotomy for the Correction of Vertical Maxillary Excess: A Prospective Study. Journal of maxillofacial and oral surgery, 18(1), pp. 139-146.

Jeevanandan, G. (2017). Kedo-S Paediatric Rotary Files for Root Canal Preparation in Primary Teeth - Case Report. Journal of clinical and diagnostic research: JCDR, 11(3), pp. ZR03-ZR05.

Jeevanandan, G. and Govindaraju, L. (2018). Clinical comparison of Kedo-S paediatric rotary files vs manual instrumentation for root canal preparation in primary molars: a double blinded randomised clinical trial. European archives of paediatric dentistry: official journal of the European Academy of Paediatric Dentistry, 19(4), pp. 273-278.

Jose, J., Ajitha and Subbaiyan, H. (2020). Different treatment modalities followed by dental practitioners for Ellis class 2 fracture - A questionnaire-based survey. The open dentistry journal, 14(1), pp. 59-65.

Ke, Y. et al. (2019). Photosynthesized gold nanoparticles from Catharanthus roseus induces caspase-mediated apoptosis in cervical cancer cells (HeLa). Artificial cells, nanomedicine, and biotechnology, 47(1), pp. 19381946.

Khan, S. Q. (2014). Dental caries in Arab League countries: a systematic review and meta-analysis. International dental journal, 64(4), pp. 173-180.

Krishnaswamy, H. et al. (2020). Investigation of air conditioning temperature variation by modifying the structure of passenger car using computational fluid dynamics. Thermal science, 24(1 Part B), pp. 495-498. Lith, A., Lindstrand, C. and Gröndahl, H.-G. (2002). Caries development in a young population managed by a restrictive attitude to radiography and operative 
intervention: II. A study at the surface level. Dento maxillo facial radiology, 31(4), pp. 232-239.

Mahesh R, M. M. (2018). Fluoride, Fluoridated Toothpaste Efficacy and Its Safety In Children - Review. International Journal of Pharmaceutical Research, 10(04). doi: 10.31838/ ijpr/2018.10.04.017.

Malli Sureshbabu, N. et al. (2019). Concentrated Growth Factors as an Ingenious Biomaterial in Regeneration of Bony Defects after Periapical Surgery: A Report of Two Cases. Case reports in dentistry, 2019, p. 7046203.

Mathew, M. G. et al. (2020). Evaluation of adhesion of Streptococcus mutans, plaque accumulation on zirconia and stainless steel crowns, and surrounding gingival inflammation in primary. Clinical oral investigations.

McDonald, S. P. and Sheiham, A. (1992). The distribution of caries on different tooth surfaces at varying levels of caries--a compilation of data from 18 previous studies. Community dental health, 9(1), pp. 39-48.

Mehta, M. et al. (2019). Oligonucleotide therapy: An emerging focus area for drug delivery in chronic inflammatory respiratory diseases. Chemico-biological interactions, 308, pp. 206-215.

Muthukrishnan, S. et al. (2020). Support vector machine for modelling and simulation of heat exchangers. Thermal science, 24(1 Part B), pp. 499-503.

Nair, M. et al. (2018). Comparative evaluation of postoperative pain after pulpectomy with k-files, kedo-s files and mtwo files in deciduous molars -a randomized clinical trial. Brazilian Dental Science, p. 411. doi: 10.14295/ bds.2018.v21i4.1617.

Nordblad, A. and Larmas, M. A. (1986). Caries and fillings in the permanent dentition of cohorts of schoolchildren in Espoo, Finland. Community dentistry and oral epidemiology, 14(5), pp. 271-273.

Packiri, S., Gurunathan, D. and Selvarasu, K. (2017). Management of Paediatric Oral Ranula: A Systematic Review. Journal of clinical and diagnostic research: JCDR, 11(9), pp. ZE06-ZE09.

Panchal, V., Jeevanandan, G. and Subramanian, E. M. G. (2019). Comparison of instrumentation time and obturation quality between hand K-file, H-files, and rotary Kedo-S in root canal treatment of primary teeth: A randomized controlled trial. Journal of Indian Society of Pedodontics and Preventive Dentistry, p. 75. doi: 10.4103/jisppd. jisppd_72_18.

Pc, J., Marimuthu, T. and Devadoss, P. (2018). Prevalence and measurement of anterior loop of the mandibular canal using CBCT: A cross sectional study. Clinical implant dentistry and related research. Available at: https:// europepmc.org/article/med/29624863.

Ramadurai, N. et al. (2019). Effectiveness of $2 \%$ Articaine as an anesthetic agent in children: randomized controlled trial. Clinical oral investigations, 23(9), pp. 3543-3550.
Ramesh, A. et al. (2018). Comparative estimation of sulfiredoxin levels between chronic periodontitis and healthy patients - A case-control study. Journal of periodontology, 89(10), pp. 1241-1248.

Ravikumar, D., Jeevanandan, G. and Subramanian, E. M. G. (2017). Evaluation of knowledge among general dentists in treatment of traumatic injuries in primary teeth: A cross-sectional questionnaire study. European journal of dentistry, 11(2), pp. 232-237.

Samuel, M. S. et al. (2019). Efficient removal of Chromium (VI) from aqueous solution using chitosan grafted graphene oxide (CS-GO) nanocomposite. International journal of biological macromolecules, 121, pp. 285-292. Samuel, S. R., Acharya, S. and Rao, J. C. (2020). School Interventions-based Prevention of Early-Childhood Caries among 3-5-year-old children from very low socioeconomic status: Two-year randomized trial. Journal of public health dentistry, 80(1), pp. 51-60.

Sathish, T. and Karthick, S. (2020). Wear behaviour analysis on aluminium alloy 7050 with reinforced SiC through taguchi approach. Journal of Japan Research Institute for Advanced Copper-Base Materials and Technologies, 9(3), pp. 3481-3487.

Sharma, P. et al. (2019). Emerging trends in the novel drug delivery approaches for the treatment of lung cancer. Chemico-biological interactions, 309, p. 108720.

Somasundaram, S. et al. (2015). Fluoride Content of Bottled Drinking Water in Chennai, Tamilnadu. Journal of clinical and diagnostic research: JCDR, 9(10), pp. ZC32-4.

Sridharan, G. et al. (2019). Evaluation of salivary metabolomics in oral leukoplakia and oral squamous cell carcinoma. Journal of oral pathology \& medicine: official publication of the International Association of Oral Pathologists and the American Academy of Oral Pathology, 48(4), pp. 299-306.

Subramanyam, D. et al. (2018). Comparative evaluation of salivary malondialdehyde levels as a marker of lipid peroxidation in early childhood caries. European journal of dentistry, 12(1), pp. 67-70.

Taani, D. S. M. Q. and Quteish, D. S. (2004). Oral health in Jordan. International Dental Journal, pp. 395-400. doi: 10.1111/j.1875-595x.2004.tb00017.x.

Varghese, S. S., Ramesh, A. and Veeraiyan, D. N. (2019). Blended Module-Based Teaching in Biostatistics and Research Methodology: A Retrospective Study with Postgraduate Dental Students. Journal of dental education, 83(4), pp. 445-450.

Venu, H., Raju, V. D. and Subramani, L. (2019). Combined effect of influence of nano additives, combustion chamber geometry and injection timing in a DI diesel engine fuelled with ternary (diesel-biodiesel-ethanol) blends. Energy, 174 , pp. 386-406. 
Venu, H., Subramani, L. and Raju, V. D. (2019). Emission reduction in a DI diesel engine using exhaust gas recirculation (EGR) of palm biodiesel blended with $\mathrm{TiO} 2$ nano additives. Renewable Energy, 140, pp. 245-263.

Vignesh, R. et al. (2019). Management of Complicated Crown-Root Fracture by Extra-Oral Fragment Reattachment and Intentional Reimplantation with 2 Years Review. Contemporary clinical dentistry, 10(2), pp. 397-401.

Vijayashree P. J. (2019). In silico validation of the non-antibiotic drugs acetaminophen and ibuprofen as antibacterial agents against red complex pathogens. Journal of periodontology, 90(12), pp. 1441-1448.
Warren, J. J., Hand, J. S. and Yao, J. H. (1997). Firstmolar caries experience among Taiwanese first-grade children. ASDC journal of dentistry for children, 64(6), pp. 425-428.

World Health Organization WHO. (1997). Oral health surveys: basic methods. 4th ed. WHO.

Wyne, A. H. (2008). Caries prevalence, severity, and pattern in preschool children. The journal of contemporary dental practice, 9(3), pp. 24-31.

Wyne, A. H. et al. (2002). Caries prevalence in Saudi primary schoolchildren of Riyadh and their teachers' oral health knowledge, attitude and practices. Saudi medical journal, 23(1), pp. 77-81. 